\title{
Evaluation of bone formation and membrane degradation in guided bone regeneration using a 4-hexylresorcinol-incorporated silk fabric membrane
}

\author{
Sang-Woon Lee ${ }^{1 *}$, In Chul Um², Seong-Gon Kim ${ }^{3}$ and Min-Sang Cha ${ }^{1}$
}

\begin{abstract}
Background: The aims of present study were (1) to evaluate new bone formation among the 4-hexylresorcinol (4HR)-incorporated silk fabric membrane (SFM), conventional SFM, and uncovered control groups and (2) to compare the amount of residual membrane between the 4HR-incorporated SFM and conventional SFM in a rabbit parietal defect model.

Methods: Nine New Zealand white rabbits were used for this animal study. After the formation of a bilateral parietal bone defect (diameter $8.0 \mathrm{~mm}$ ), either 4HR-incorporated SFM or conventional SFM was grafted into the defect. The defect in the control was left uncovered. New bone formation and the amount of residual membrane were evaluated by histomorphometry at 8 weeks after the operation.

Results: The total amount of new bone was $37.84 \pm 8.30 \%$ in the control, $56.64 \pm 15.74 \%$ in the 4HR-incorporated SFM group, and $53.35 \pm 10.52 \%$ in the conventional SFM group 8 weeks after the operation. The differences were significant between the control and 4HR-incorporated SFM group $(P=0.016)$ and between the control and conventional SFM group $(P=0.040)$. The residual membrane was $75.08 \pm 10.52 \%$ in the 4 HR-incorporated SFM group and $92.23 \pm 5.46 \%$ in the conventional SFM group 8 weeks after the operation. The difference was significant $(P=0.039)$.
\end{abstract}

Conclusions: The 4HR-incorporated SFM and conventional SFM groups showed more bone regeneration than the control group. The incorporated $4 \mathrm{HR}$ accelerated the partial degradation of the silk fabric membrane in a rabbit parietal defect model 8 weeks after the operation.

\section{Background}

The main goal of using a barrier membrane in guided bone regeneration (GBR) is to maintain a space for future bone regeneration [1]. In recent decades, absorbable collagen membranes or non-absorbable ePTFE membranes have been used for GBR in dental practice $[1,2]$. Although these commercial membranes have been shown to be effective in bone regeneration, their high cost inhibits their widespread clinical application.

\footnotetext{
* Correspondence: sangwoone@hanmail.net

'Department of Dentistry, Gangneung Asan Hospital, University of Ulsan College of Medicine, 38, Bangdong-gil, Sacheon-myeon, Gangneung-si, Gangwon-do, South Korea

Full list of author information is available at the end of the article
}

Producing a barrier membrane from silk fiber would be advantageous with respect to cost [2]. Previous studies using silk-based barrier membranes evaluated new bone formation after their application in animal models. The silk fibroin film produced by the casting method resulted in greater bone regeneration compared to uncovered controls $[3,4]$. The silkworm cocoon membrane produced by simple separation also showed greater amounts of bone regeneration compared to the ePTFE membrane [5].

However, silk-based barrier membranes have some limitations. First, they are non-absorbable. Second, surgery for the removal of the membrane is needed after adequate bone formation. Previous studies showed that the silk fibroin film exhibits high fragility and poor 
operability during the operation [3, 4]. The silkworm cocoon membrane showed better bone formation compared to the ePTFE membrane [5]. However, the mechanical separation of the silkworm cocoon may be labor intensive and difficult to automate.

In the present study, the silk fabric membrane (SFM) was tested as another silk-based barrier membrane in the animal model. The SFM is produced by a textile manufacturing method. The antiseptic agent 4-hexylresorcinol (4HR) was also incorporated into the SFM for drug release [4]. 4HR has been used as a component of sore throat lozenges [6]. A previous study reported that $4 \mathrm{HR}$ may accelerate the degradation of the silk fibroin graft by increasing the activation of macrophages [7]. We thus hypothesized that the degradation of the SFM would be accelerated by the release of $4 \mathrm{HR}$.

The aims of present study were (1) to evaluate new bone formation among the 4HR-incorporated SFM, conventional SFM, and uncovered control groups and (2) to compare the amount of residual membrane between the 4HR-incorporated SFM and conventional SFM in a rabbit parietal defect model.

\section{Methods}

\section{Silk fabric membrane}

The silk fabric membrane (SFM) was kindly provided by Sanju Myungju Co (Sangju, Korea). The silk fabric is the plain weave with a waft density of 45 yarns/inch and a weft density of 47 yarns/inch. The waft yarn is a 140denier silk filament, and the weft yarn is a twisted yarn from $21 \mathrm{~d}$ to $25 \mathrm{~d}$ silk filaments. This silk fabric membrane was degummed to remove sericin before the experiment. The crystallinity of silk fabric is $55.7 \%$ calculated from Fourier transform infrared spectroscopy measurement result. The average pore size of silk fabric membrane is $12,792 \mu \mathrm{m}^{2}$ determined by digital optical microscope (Toolis, Daegu, Korea).

The SFM was prepared with $10 \mathrm{~mm}$ in length and $10 \mathrm{~mm}$ in width for animal experiment. The thickness of SFM was approximately $0.3 \mathrm{~mm}$ in dry condition and $0.5 \mathrm{~mm}$ in wet condition.

\section{Animals and surgical procedures}

Nine 10-week-old New Zealand white rabbits were used in this experiment, which was approved by the Institutional Animal Care and Use Committee of GangneungWonju National University, Gangneung, Korea (IACUC GWNU- 2014-15). General anesthesia was induced by intramuscular injection of a combination of $0.5 \mathrm{~mL}$ of tiletamine and zolazepam (125 mg/mL; Zoletil; Bayer Korea, Seoul, Korea) and $0.5 \mathrm{~mL}$ of xylazine hydrochloride (10 mg/kg body weight; Rompun; Bayer Korea). The cranium area was shaved and disinfected with povidineiodine. A longitudinal incision was made on the midline of the cranium area. Sharp subperiosteal dissection was performed to expose the parietal bones. A dental trephine bur was used under saline irrigation to create a bilateral full-thickness calvarial defect. Two defects $8 \mathrm{~mm}$ in diameter were created, one on each side of the midline. Either the 4HR-incorporated SFM or the conventional SFM was placed on the calvarial defects. Some defects remained uncovered and served as the control (Fig. 1). Assignment to each group for the corresponding defect was performed randomly, and each group was composed of six animals (six defects for each group). None of the animals received the same membrane in both calvarial defects. Then, the pericranium and skin were closed in layers with 3-0 black silk. Each rabbit was

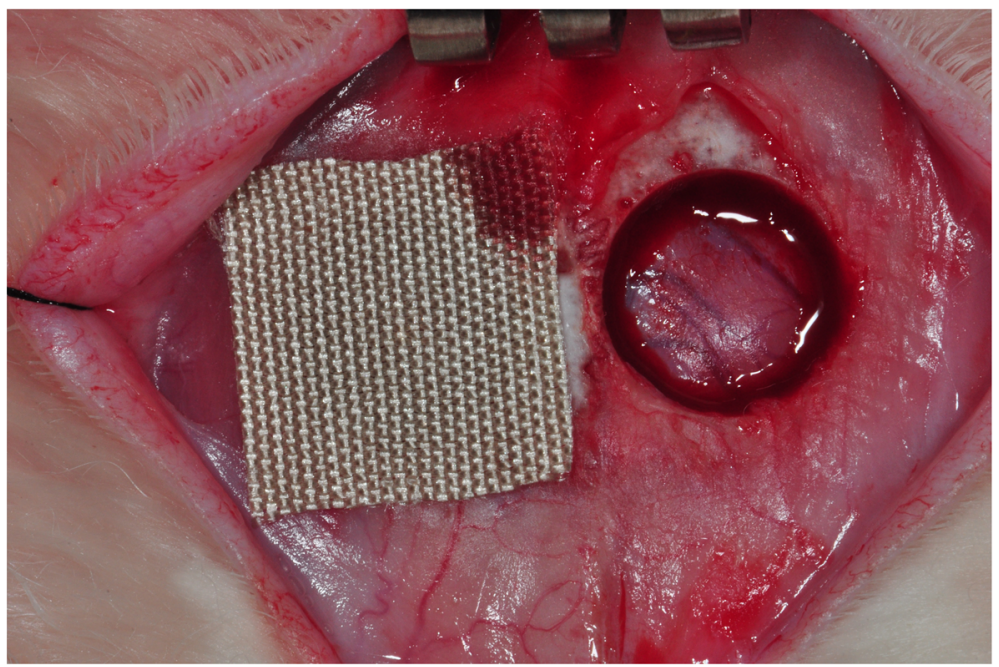

Fig. 1 Bilateral parietal bone defect of rabbits. The right side contained 4HR-incorporated SFM, and the left side served as the uncovered control. 4HR 4-hexylresorcinol, SFM silk fabric membrane 
individually caged and received food and water. Nine animals were sacrificed at 8 weeks after the operation.

\section{Hematoxylin and eosin staining}

The bone samples were decalcified using $5 \%$ nitric acid for $48 \mathrm{~h}$. The right and left parietal bones were separated through the midline sagittal suture. Both segments were embedded to show the sagittal sections in the paraffin blocks. Then, the sections were sliced and stained with hematoxylin and eosin (H\&E).

Paraffin-embedded tissue blocks were sliced to a thickness of $5 \mu \mathrm{m}$. The sections of each tissue were carefully placed on silane-coated slides. These slides were incubated at $60{ }^{\circ} \mathrm{C}$ for $24 \mathrm{~h}$. After cooling at room temperature, the tissue slides were soaked in $100 \%$ xylene for $5 \mathrm{~min}$ in triplicate. The tissue sections were then hydrated by the consecutive application of high- to low-grade ethyl alcohol. Fully hydrated tissue sections were washed with distilled water. After that, tissue sections were stained with Harris modified hematoxylin solution (Sigma Aldrich, St. Louis, MO, USA) for $10 \mathrm{~min}$ at room temperature. Then, de-staining was performed with $1 \%$ acid alcohol for $1 \mathrm{~s}$. De-stained tissue sections were washed in running tap water for $10 \mathrm{~min}$. Next, Eosin Y solution (Sigma Aldrich, St. Louis, MO, USA) was applied on the tissue sections for $1 \mathrm{~min}$. Then, after gradational hydration with ethyl alcohol and clearing with xylene, the tissue sections were fixed by paramount solutions.

\section{Histomorphometric evaluation}

The sagittal section showing the widest defect area was selected. Digital images of the selected sections were taken using a digital camera (DP-20; Olympus, Tokyo, Japan). The images were analyzed by SigmaScan Pro 5.0; SPSS Science, Chicago, IL, USA). The total amount of new bone was calculated as a percentage of the total region of the defect. The residual membrane was also calculated as a percentage of the residual membrane area 8 weeks postoperatively compared to the original area of membrane.

\section{Statistical analysis}

An ANOVA test was used for comparison of new bone formation of the three groups, and the LSD method was used as a post hoc test. An independentsamples $t$ test was used for the comparison of the residual membrane of the two groups. Statistical significance was set at $P<0.05$.

\section{Results}

The histomorphometry results are presented in Table 1 . Total new bone was $37.84 \pm 8.30 \%$ in the control group, $56.64 \pm 15.74 \%$ in the 4HR-incorporated SFM group,
Table 1 Histomorphometric analysis

\begin{tabular}{lccl}
\hline & Control & $\begin{array}{l}\text { 4HR incorporated } \\
\text { SFM }\end{array}$ & $\begin{array}{l}\text { Conventional } \\
\text { SFM }\end{array}$ \\
\hline Total new bone (\%) & $37.84 \pm 8.30$ & $56.64 \pm 15.74^{*}$ & $53.35 \pm 10.52$ \\
Residual membrane (\%) & & $75.08 \pm 10.52$ & $92.23 \pm 5.46$ \\
\hline
\end{tabular}

4HR 4-hexylresorcinol, SFM silk fabric membrane

${ }^{*} P<0.05$ compared to uncovered control

and $53.35 \pm 10.52 \%$ in the conventional SFM group 8 weeks after the operation. The differences were significant between the control and 4HR incorporated SFM group $(P=0.016)$ and the control and conventional SFM group $(P=0.040)$.

The residual membrane was $75.08 \pm 10.52 \%$ in the 4HR-incorporated SFM group and $92.23 \pm 5.46 \%$ in the conventional SFM group at 8 weeks after the operation. The difference was significant $(P=0.039)$. The SFM was encapsulated by thick fibrotic tissue in the SFM group (Fig. 2). The thickness of the SFM in the conventional SFM group was approximately $0.5 \mathrm{~mm}$, almost the same as in the original dimension of the SFM. However, the thickness of the SFM in the 4HR-incorporated SFM group was approximately $0.2 \mathrm{~mm}$.

\section{Discussion}

Silk fiber is composed of fibroin and sericin. Silk fibroin is a main protein that shows biocompatibility and a low immune response in the human body [8]. Silk sericin is a gummy protein that surrounds the silk fibroin. It has been considered to be a biocompatible material; however, immune and irritation reactions to silk sericin have been reported $[9,10]$. The SFM in present study, silk sericin was removed by degumming process.

The conventional SFM showed a soft and smooth texture with ivory color (Fig. 1). The main advantage of the conventional SFM is that it is possible to mass-produce with uniform quality and low cost. In clinical application, it can be applied on small- to large-sized bone defects, and the shaping of the membrane can be easily performed by a scissor. The disadvantages of the conventional SFM are that it has low rigidity and is nonabsorbable because of high molecular weight and crystallinity of natural silk material; thus, a second surgery for removal is needed.

In the present study, the 4HR-incorporated SFM group and the conventional SFM group showed higher bone regeneration compared to uncovered controls $(P=0.016$ and $P=0.040$, Table 1 ). These results are consistent with previous studies concerning the use of other types of silkbased barrier membranes [3, 4]. The conventional SFM is used as a barrier membrane to prevent soft tissue ingrowth during bone regeneration. When comparing the 4HR-incorporated SFM and the conventional SFM groups, there was no significant difference $(P>0.05)$. 
The main advantage of the use of collagen membranes is its gradual resorption during bone regeneration [11]. If the addition of $4 \mathrm{HR}$ can lead to complete resorption of the silk membrane, a second surgery for membrane removal is not needed, as in the case of collagen membranes. On the contrary, silk is mostly considered to be a non-absorbable material [12]. However, some studies have reported that the degradation of silk fibroin may be possible after a long period of time in vivo $[9,13]$. Silk fibroin can be slowly degraded by proteolytic enzymes in vivo and vitro $[9,14-16]$. Macrophages have an important role in the phagocytosis of foreign particles and in the release of proteolytic enzymes [17]. 4HR may increase macrophage activation through the suppression of foreign body giant cell formation in the silk fibroin graft [7].

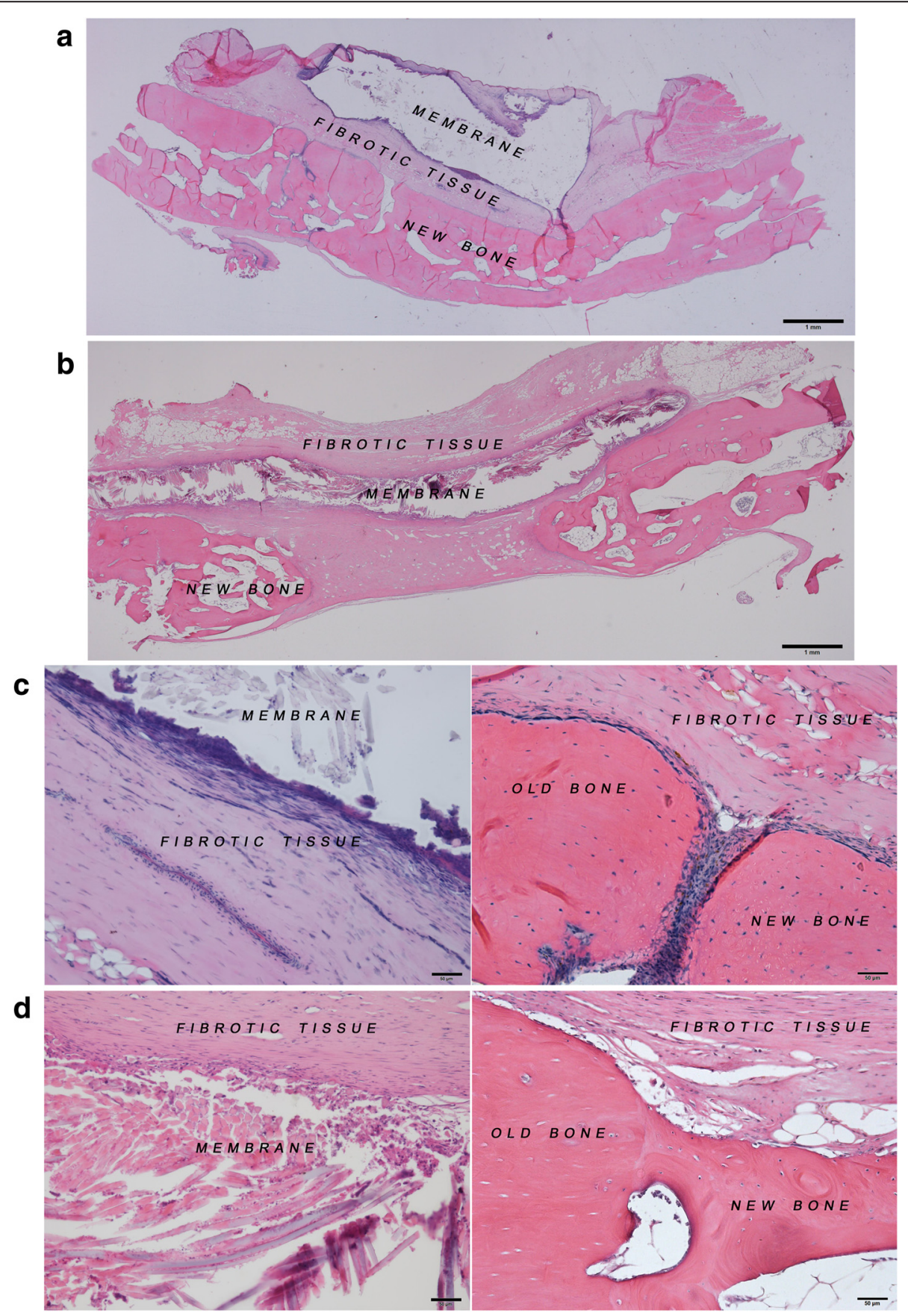

Fig. 2 Histological images at 8 weeks after the operation. a 4HR-incorporated SFM (bar =1 mm). b Conventional SFM (bar $=1 \mathrm{~mm})$. c 4 HR-incorporated SFM (bar $=50 \mu \mathrm{m})$. d Conventional SFM (bar $=50 \mu \mathrm{m})$ 
In this study, the amount of residual membrane was higher in the conventional SFM group compared to 4HR-incorporated SFM group $(P=0.039$, Fig. 2$)$. This means that the addition of $4 \mathrm{HR}$ accelerates the partial degradation of the SFM. The SFM should be fully absorbed in order to be clinically meaningful. However, complete resorption of the SFM was not observed in the present study. Further studies with longer healing periods and different concentrations of $4 \mathrm{HR}$ are needed to evaluate the effect of $4 \mathrm{HR}$ with respect to the degradation of silk fibroin.

\section{Conclusions}

The SFM groups showed more bone regeneration than the uncovered control group. The incorporated 4HR accelerated the partial degradation of the silk fabric membrane in a rabbit parietal defect model 8 weeks after the operation.

\section{Abbreviations}

4HR: 4-hexylresorcinol; ePTFE: expanded polytetrafluoroethylene; SFM: silk fabric membrane.

\section{Competing interests}

The authors declare that they have no competing interests.

\section{Authors' contribution}

IC and SG participated in the design of this study, histology, and manuscript revision. MS participated in the manuscript revision. SW participated in the animal study, histology, and data analysis and drafted the manuscript. All authors read and approved the final manuscript.

\section{Acknowledgments}

This work was supported by a grant from the Next-Generation BioGreen 21 Program (center for Nutraceutical \& Pharmaceutical Materials no. PJ01121404) of the Rural Development Administration, Republic of Korea.

\section{Author details}

'Department of Dentistry, Gangneung Asan Hospital, University of Ulsan College of Medicine, 38, Bangdong-gil, Sacheon-myeon, Gangneung-si, Gangwon-do, South Korea. ${ }^{2}$ Department of Bio-fibers and Materials Science, Kyungpook National University, Daegu, South Korea. ${ }^{3}$ Department of Oral and Maxillofacial Surgery, College of Dentistry, Gangneung-Wonju National University, Gangneung-si, South Korea.

Received: 3 August 2015 Accepted: 21 September 2015

Published online: 30 September 2015

\section{References}

1. Hermann JS, Buser D (1996) Guided bone regeneration for dental implants. Curr Opin Periodontol 3:168-77

2. Lee SW, Kim SG (2014) Membranes for the guided bone regeneration. J Korean Assoc Maxillofac Plast Reconstr Surg 36:239-46

3. Song JY, Kim SG, Lee JW, Chae WS, Kweon H, Jo YY et al (2011) Accelerated healing with the use of a silk fibroin membrane for the guided bone regeneration technique. Oral Surg Oral Med Oral Pathol Oral Radiol Endod 112:e26-e33

4. Lee SW, Kim SG, Song JY, Kweon H, Jo YY, Lee KG et al (2013) Silk fibroin and 4-hexylresorcinol incorporation membrane for guided bone regeneration. J Craniofac Surg 24:1927-30

5. Ha YY, Park YW, Kweon H, Jo YY, Kim SG (2014) Comparison of the physical properties and in vivo bioactivities of silkworm-cocoon-derived silk membrane, collagen membrane, and polytetrafluoroethylene membrane for guided bone regeneration. Macromol Res 22:1018-23

6. McNally D, Shephard A, Field E (2012) Randomised, double-blind, placebocontrolled study of a single dose of an amylmetacresol/2, 4-dichlorobenzyl alcohol plus lidocaine lozenge or a hexylresorcinol lozenge for the treatment of acute sore throat due to upper respiratory tract infection. J Pharm Pharm Sci 15:281-94

7. Kweon H, Kim SG, Choi JY (2014) Inhibition of foreign body giant cell formation by 4-hexylresorcinol through suppression of diacylglycerol kinase delta gene expression. Biomaterials 35:8576-84

8. Kundu B, Rajkhowa R, Kundu SC, Wang X (2013) Silk fibroin biomaterials for tissue regenerations. Adv Drug Deliv Rev 65:457-70

9. Altman GH, Diaz F, Jakuba C, Calabro T, Horan RL, Chen J et al (2003) Silk-based biomaterials. Biomaterials 24:401-16

10. Aramwit P, Kanokpanont S, De-Eknamkul W, Srichana T (2009) Monitoring of inflammatory mediators induced by silk sericin. J Biosci Bioeng 107:556-61

11. Schwartzmann M (2000) Use of collagen membranes for guided bone regeneration: a review. Implant Dent 9:63-6

12. Postlethwait R (1970) Long-term comparative study of nonabsorbable sutures. Ann Surg 171:892

13. Cao Y, Wang B (2009) Biodegradation of silk biomaterials. Int J Mol Sci 10:1514-24

14. Lam K, Nijenhuis A, Bartels $H$, Postema A, Jonkman M, Pennings A et al (1995) Reinforced poly (L-lactic acid) fibres as suture material. J Appl Biomater 6:191-7

15. Salthouse TN, Matlaga BF, Wykoff MH (1977) Comparative tissue response to six suture materials in rabbit cornea, sclera, and ocular muscle. Am J Ophthalmol 84:224-33

16. Minoura N, Tsukada M, Nagura M (1990) Physico-chemical properties of silk fibroin membrane as a biomaterial. Biomaterials 11:430-4

17. Deodhar AK, Rana R (1997) Surgical physiology of wound healing: a review. J Postgrad Med 43:52

\section{Submit your manuscript to a SpringerOpen ${ }^{\odot}$ journal and benefit from:}

- Convenient online submission

- Rigorous peer review

- Immediate publication on acceptance

- Open access: articles freely available online

- High visibility within the field

- Retaining the copyright to your article

Submit your next manuscript at $>$ springeropen.com 